\title{
Taking it Global: Structuring Global Health Education in Residency Training
}

\author{
Gitanjli Arora, MD, DTMH', Jonathan Ripp, MD, MPH², Jessica Evert, $M D^{3}$, Tracy Rabin, $M D, S M^{4}$, \\ Janis P. Tupesis, $M D^{5,6}$, and James Hudspeth, $M D^{7}$
}

'Department of Palliative Medicine, Kaiser Permanente Los Angeles, Los Angeles, CA, USA; ${ }^{2}$ Department of Medicine, Icahn School of Medicine at Mount Sinai, New York, NY, USA; ${ }^{3}$ Department of Family and Community Medicine, University of California San Francisco, San Francisco, CA, USA; ${ }^{4}$ Department of Internal Medicine, Yale School of Medicine, New Haven, CT, USA; ${ }^{5}$ Department of Emergency Medicine, University of Wisconsin School of Medicine and Public Health, Madison, WI, USA; ${ }^{6}$ Global Health Institute, University of Wisconsin School of Medicine and Public Health, Madison, WI, USA; ' Department of Internal Medicine, Boston University, Boston, MA, USA.

To meet the demand by residents and to provide knowledge and skills important to the developing physician, global health $(\mathrm{GH})$ training opportunities are increasingly being developed by United States (U.S.) residency training programs. However, many residency programs face common challenges of developing GH curricula, offering safe and mentored international rotations, and creating $\mathrm{GH}$ experiences that are of service to resource-limiting settings. Academic GH partnerships allow for the opportunity to collaborate on education and research and improve health care and health systems, but must ensure mutual benefit to U.S. and international partners. This article provides guidance for incorporating $\mathrm{GH}$ education into U.S. residency programs in an ethically sound and sustainable manner, and gives examples and solutions for common challenges encountered when developing $\mathrm{GH}$ education programs.

KEY WORDS: Global health education; Residency training. J Gen Intern Med 32(5):559-62

DOI: $10.1007 / \mathrm{s} 11606-016-3843-7$

(c) Society of General Internal Medicine 2016

$\mathrm{G}$ lobal health $(\mathrm{GH})$, the study, research, and practice that prioritizes achieving equity in health for all people, ${ }^{1}$ has developed into an academic discipline. Medical students report increased exposure to $\mathrm{GH}$ education and residents increasingly select training programs based on $\mathrm{GH}$ opportunities with steady growth programs that offer GH education., ${ }^{2,3}$ However, many programs face common challenges in developing and supporting GH education. This article provides guidance for incorporating GH education into U.S. residency programs.

Electronic supplementary material The online version of this article (doi:10.1007/s11606-016-3843-7) contains supplementary material, which is available to authorized users.

Received May 3, 2016

Revised July 12, 2016

Accepted August 2, 2016

Published online August 16, 2016
Aside from meeting resident demands, GH education addresses content areas essential to the developing physician; these include broadened medical knowledge, cultural humility, resource utilization, understanding of social determinants of health, and appreciation for public health and preventive medicine. ${ }^{4,5}$ These areas of focus are included in the Next Accreditation System of the Accreditation Council for Graduate Medical Education (ACGME). ${ }^{6}$ In addition to the knowledge and skills acquired through GH education, ${ }^{5,7,8}$ residents with GH experience have increased interest in primary care and in serving underserved and diverse populations, ${ }^{4,9-11}$ thereby benefiting the U.S. healthcare system.

A number of common challenges face $\mathrm{GH}$ education efforts, including: lack of access to didactic GH curricula and/or faculty expertise, limited partnerships with international institutions, concerns of burdening international partners rather than being of service, insufficient program funding, low levels of institutional support, and a multitude of logistical, legal, regulatory and administrative barriers. To address these challenges, it is essential to identify the needs of the learners, goals of the program, and resources. If GH educational experiences are developed with international partners, then it is of utmost importance to consider the needs of the international partner. We propose a systematic approach using four fundamental questions to guide the development or refinement of academic GH programs: Who are you teaching?; How are you teaching?; What are the goals of your GH program?; and What are your resources?.

\section{WHO ARE YOU TEACHING?}

Needs assessments to identify learner interest and prior level of experience inform the type and amount of resources needed in developing a GH program. To create effective curricula, residency programs must also have an understanding of $\mathrm{GH}$ core content areas. ${ }^{12}$

If the GH program includes sending U.S. residents to international partners, the U.S. residency program should be prepared to reciprocally host trainees and faculty from the international partner if desired by the international partner. 
Globally there exist severe shortages in trained health professionals, ${ }^{13}$ and hosting international learners offers the opportunity to strengthen knowledge and skills to benefit health systems of GH partners. Hosting learners from international partners similarly requires needs assessments of those learners, communication about goals and objectives, pre-departure preparation, administrative and logistic support, and curriculum development. Hosting international learners also contributes GH education at the U.S. institution through sharing of medical knowledge, resource utilization, and cultural awareness.

\section{HOW ARE YOU TEACHING?}

The ACGME competencies emphasize assessing progress toward independent practice. ${ }^{6}$ Simultaneously, there have been increasing efforts to integrate best practices for $\mathrm{GH}$ programs at academic institutions, specifically focusing on educational objectives, ethical engagement of learners and institutions, and the development of sustainable partnerships. Conceptual frameworks for educational outcomes ${ }^{14}$ and competency-based curricula ${ }^{15-18}$ now exist to guide developing $\mathrm{GH}$ programs.

In considering how residents are taught, it is important to note that while international rotations provide many training benefits, these experiences are not essential to GH education. A variety of experiences at the home institution can provide the foundation for GH education within a given specialty, including didactic lectures and seminar series on GH topics; GH journal and book clubs; and training on health, safety, and cultural humility. Although not comprehensive, the Online Table provides a list of online GH learning resources. Opportunities to strengthen GH clinical skills also include "local global health" efforts to achieve health equity domestically in rural and urban underserved locations, Native American communities, refugee clinics, and rotations in travel medicine clinics.

For GH programs with international rotations, these rotations must not occur in place of GH curricula at the residents' home institution. To ensure resident health, patient safety, and to minimize burden on international partners, residents must be adequately prepared and supported. GH educators have noted that no clinical trainee would provide patient care in a U.S. hospital without appropriate guidance for their training experience, and the same support should be provided for residents engaging in international rotations. ${ }^{19}$ Others have further argued that clinical practice and autonomy should be decreased where residents are functioning outside of their usual frame of references of culture, language, diagnostic tools, and treatment protocols. ${ }^{20}$ Regardless of structure of clinical experience, support for residents engaging in $\mathrm{GH}$ rotations must include clear communication of learning goals and objectives, pre-departure training, curriculum, logistic and administrative support, debriefing on return, evaluation, and feedback from GH partner faculty. ${ }^{21}$ Increasingly and appropriately, the onus is on U.S. residency programs to ensure that U.S. residents adhere to GH best practices. ${ }^{22-25}$

\section{WHAT ARE THE GOALS OF YOUR GH PROGRAM?}

GH programs are often developed out of a desire to achieve equity in health for all people, regardless of geographic location. This desire to be of service may take the form of U.S. residents traveling to resource-constrained settings for shortterm rotations. ${ }^{16}$ However, ethical practice guidelines for $\mathrm{GH}$ recognize there may be unintended consequences of training experiences. ${ }^{26}$ Residents in unfamiliar clinical environments and with differing levels of supervision may negatively impact patient care, community relations, and place substantial burdens on educators already constrained by limited resources. Attempts by residents to provide care can result in harm if resource utilization, cultural context, and sustainability are not carefully considered. GH experiences that benefit the learner at the expense of patients and educators negate the desire to be of service and such harms must be avoided.

GH programs with international rotations can be designed to provide benefit and minimize the administrative and logistic burdens associated with hosting learners. Academic GH programs are increasingly developing longstanding partnerships with international institutions and nesting individual shortterm learning experiences within longitudinal partnerships. ${ }^{16}$ GH partnerships allow a better understanding of respective needs that over time may transcend cultural barriers and power differentials which otherwise limit communication. Longstanding collaborative research projects or educational efforts involving bilateral exchange, telemedicine, or other knowledge and skills transfer may have benefits to the international partner that offset the burdens associated with hosting short-term learners.

\section{WHAT ARE YOUR RESOURCES?}

Given the tremendous interest among U.S. residents in GH education, residents motivated to strengthen $\mathrm{GH}$ knowledge may coordinate lecture series, journal clubs, access $\mathrm{GH}$ webinars, utilize simulation, ${ }^{27}$ and build curricula. In keeping with the principles of adult learning theory, and recognizing that GH programs are often challenged by a lack of salarysupported and/or experienced GH faculty, engaging residents to develop independent learning activities may be helpful.

Curricular aspects of global health programs are available online from various organizations. In particular, model curricula are available from MedEdPortal ${ }^{28,29}$ and through professional organizations.

Residents may also identify faculty to provide mentorship for GH educational, clinical, and/or research interests. These faculty may have existing international partnerships within which short-term resident GH rotations may further strengthen 
ongoing research and/or educational objectives. To ensure appropriate mentorship, supervision, and evaluation of residents and to support sustained collaborations with GH partners, having dedicated GH faculty with salary support is advisable.

GH programs with international rotations must be able to support learners safely, ethically, and with mentorship. Effective preparation and ongoing supervision ensures that residents practice within their scope of training, thereby minimizing risk of harm to patients, themselves, and their affiliated programs. ${ }^{30}$ An alternative to creating de novo international rotations is for residents to engage with existing $\mathrm{GH}$ experiential offerings. GH service-learning organizations have international partnerships and reciprocity models, and offer continuity with host communities, programmatic accountability, and administrative oversight. These collaborations, when operationalized astutely, afford for ethical and sustainable GH rotations within U.S. residency programs. They are particularly useful for programs without existing international partnerships or with insufficient administrative resources to ensure safety, quality, and ethical or academic rigor. ${ }^{31}$

For programs developing partnerships with international institutions, international partners must share in the development of goals and objectives for international rotations. Partner faculty are likely better able to advise on experiences at their institution that can best meet the rotation objectives. As international partnering faculty provide mentorship, education, evaluation and support to rotating residents, partner faculty should be asked how best to recognize their teaching contributions. Partner faculty may benefit from faculty appointment at the U.S. residency program, involvement in national or international educational conferences, or other formal recognition of GH educational commitment.

Whether collaborating with already established academic GH relationships through partnership with existing GH experiential offerings, or creating new GH partnerships, best practice guidelines provide conceptual and operational guidance to ensure ethical GH programs. ${ }^{26}$ Key recommendations include recognizing and compensating the true costs to partners, ensuring practice within trainee level of competency, and evaluating the impacts, both constructive and critical, of programs on partners and host communities.

For robust GH educational programs with $\mathrm{GH}$ tracks or pathways, the GH agenda must be integrated into the institutional GME structure. Strategic alignment of GH programs with the objectives of the larger academic institution, the GME Office, and residency program allows for support by the institution's administrative leaders. Similarly, sustainable funding structures need to be identified to support these programs.

The collective expertise of lessons learned from successful GH programs is available through a growing body of $\mathrm{GH}$ education literature and mentorship programs such as the Consortium of Universities for Global Health Program Advisory Service (GHPAS); see Online Table. GHPAS provides a yearlong program in which mentees are paired with a mentor selected to address specific needs and guide program development.

\section{NEXT STEPS}

In considering the resources required to ensure safe, supported, and sustainable GH rotations, the administrative details of multiple GH programs at a single institution could benefit from centralized oversight and implementation. New and innovative ways to integrate GME trainees under institutional medical malpractice insurance and employee health programs while on international rotations need to be identified, disseminated and shared as best practice. Consideration needs to be given to the core administrative structure of large institutional GH programs. Should administrative activities be housed with academic departments, or consolidated within the GME office? Should residents be prepared, overseen, and assessed by faculty and program directors, or directors of GME GH programs?

Opportunities for bidirectional exchange of residents must also be developed and aim to be equitable. If U.S. rotating residents engage in clinical care during international rotations, then efforts should be made to allow international rotators to engage in the same level of learning. Alternatively, to ensure equity, patient safety, and practice within training level, rotations bilaterally can also be structured as largely shadowing experiences, with opportunities for discussion and debriefing with experienced faculty. Importantly, bidirectional exchange fosters the exchange of knowledge, skills, and attitudes among residents and is disseminated through departments. Visiting international rotators allow for exposure to important $\mathrm{GH}$ topics, contribute to widening differential diagnoses, and discuss management of diseases with fewer resources or in different cultural contexts. International rotators have been described to implement teaching strategies, such as morning report or sharing new knowledge, upon return to their home institution. ${ }^{32}$

It is essential that GH educational experiences be built thoughtfully, collaboratively, and consistent with ethical guidelines. GH programs should build on existing curricula, ensure sustainability, integrate the GH agenda into GME structure, consider partnering with established service-learning experiences, and establish mutually beneficial partnerships with international institutions.

Contributors: This manuscript builds upon concepts presented at the Consortiums of Universities in Global Health in San Francisco, California in April 2016 "Taking It Global: Building Educational Global Health Programs." We are grateful to the participants in the session whose discussion helped emphasize the need for a framework to assist academic global health programs.

Corresponding Author: Gitanjli Arora, MD, DTMH; Department of Palliative Medicine, Kaiser Permanente Los Angeles, Los Angeles, CA, USA (e-mail: gtarora@gmail.com).

\section{Compliance with Ethical Standards:}

Funders: None.

Prior Presentations: This manuscript builds upon concepts presented at a session entitled: "Taking It Global: Building Educational Global Health Programs" at Consortiums of Universities in Global Health in San Francisco, California in April 2016.

Conflict of Interest: The authors declare that they do not have any conflict of interests. 


\section{REFERENCES}

1. Koplan JP, Bond TC, Merson MH, et al. Towards a common definition of global health. Lancet. 2009;373(9679):1993-1995.

2. Jordan J, Hoffman R, Arora G, Coates W. Activated learning; providing structure in global health education at the David Geffen School of Medicine at the University of California, Los Angeles (UCLA) - a pilot study. BMC Medical Education. 2016;16:63. doi:10.1186/s12909-016-0581-9.

3. Drain PK, Holmes KK, Skeff KM, Hall TL, Gardner P. Global health training and international clinical rotations during residency: current status, needs, and opportunities. Acad Med. 2009;84(3):320-325.

4. Ramsey AH, Haq C, Gjerde CL, Rothenberg D. Career influence of an international health experience during medical school. Fam Med. 2004;36(6):412-416.

5. Federico SG, Zachar PA, Oravec CM, Mandler T, Goldson E, Brown J. A successful international child health elective: the University of Colorado Department of Pediatrics' experience. Arch Pediatr Adolesc Med. 2006; 160(2): 191-196.

6. Nasca TJ, Philibert I, Brigham T, Flynn TC. The next GME accreditation system—rationale and benefits. N Engl J Med. 2012;366:1051-1056.

7. Gladding S, Zink T, Howard C, Campagna A, Slusher T, John C. International electives at the University of Minnesota Global Pediatric Residency Program: opportunities for education in all Accreditation Council for Graduate Medical Education competencies. Acad Pediatr. 2012;12(3):245-250.

8. Thompson MJ, Huntington MK, Hunt DD, Pinsky LE, Brodie JJ. Educational effects of international health electives on U.S. and Canadian medical students and residents: a literature review. Acad Med. 2003;78(3):342-347.

9. Association of American Medical Colleges. Medical School Graduation Questionnaire. Available at https://www.aamc.org/data/. Accessed July 20, 2016.

10. Gupta AR, Wells CK, Horwitz RI, Bia FJ, Barry M. The International Health Program: the fifteen-year experience with Yale University's Internal Medicine Residency Program. Am J Trop Med. 1999;61(6):1019-1023.

11. Castillo J, Goldenhar LM, Baker RC, Kahn RS, DeWitt TG. Reflective practice and competencies in global health training: lessons for serving diverse patient populations. J Grad Med Ed. 2010;2:449-455.

12. Jogerst $\mathbf{K}$, Callender $\mathbf{B}$, Adams $\mathbf{V}$, et al. Identifying interprofessional global health competencies for 21st-century health professionals. Ann Glob Health. 2015;81(2):239-247.

13. Frenk J, Chen L, Bhutta ZA, et al. Health professionals for a new century: transforming education to strengthen health systems in an interdependent world. Lancet. 2010;376:1923-1959.

14. Bozorgmehr K, Saint VA, Tinnemann P. The 'global health' education framework: a conceptual guide for monitoring, evaluation, and practice. Globalization and Health. 2011;7:8. doi:10.1186/1744-8603-7-8.

15. Howard CR, Gladding SP, Kiguli S, Andrews JS, John CC. Development of a competency-based curriculum in global child health. Acad Med. 2011;86:521-528.
16. Suchdev PS, Ahrens K, Click E, Mcacklin L, Evangelista D, Graham E. A model for sustainable short- term international medical trips. Ambul Pediatr. 2007;7:317-320.

17. Suchdev PS, Shah A, Derby KS, et al. A proposed model curriculum in global child health for pediatric residents. Acad Pediatr. 2012;12:229-237.

18. Evert J, Stewart C, Chan K, Rosenber M, Hall TL. Developing residency training in Global Health: a guidebook. San Francisco, CA: Global Health Education Consortium; 2008.

19. Cherniak WA, Drain PK, Brewer TF. Educational objectives for international medical electives: a literature review. Acad Med. 2013;88(11):17781781.

20. Pinto A, Upshar R. Global health ethics for students. Dev World Bioethics. 2009;9(1): 1-10.

21. Torjesen K, Mandalakas A, Khan R, Duncan B. International child health electives for pediatric residents. Arch Pediatr Adolesc Med. 1999; 153(12): 1297-1302.

22. The Liason Committee on Medical Education. Functions and Structure of a Medical School. Available at www.lcme.org. Accessed July 20, 2016.

23. Evert J, Todd T, Zitek P. Do you GASP? How pre-health students delivering babies in Africa is quickly becoming consequentially unacceptable. The Advisor. 2015:61-65.

24. Todd T, Prasad S. Developing ambassadors for patient safety. The Advisor. 2015:61-63.

25. A New Mindset for Global Health Training. Available at: http://www.pih. $\mathrm{org} / \mathrm{blog} / \mathrm{dr}$--michelle-morse-a-new-mindset-for-global-health-training. Accessed July 20, 2016.

26. Crump JA, Sugarman J, Working Group on Ethics Guidelines for Global Health T. Ethics and best practice guidelines for training experiences in global health. Am J Trop Med. 2010;83(6):1178-1182.

27. Pitt MB, Gladding SP, Butteris SM. Using simulation for global health preparation. Pediatrics. 2016.

28. Lee $\mathbf{P}$, Johnson A, Rajashekara $\mathbf{S}$, et al. Clinical topics in global health: a practical introduction for pre-clinical medical students. MedEdPORTAL Publ. 2013;9:9471. doi: 10.15766/mep_2374-8265.9471 . Accessed July 20, 2016.

29. Elansary M, Kallem S, Peluso M, Thomas J, Rabin T. Global health clinical ethics. MedEdPORTAL Publ. 2015;11:10232. doi: 10.15766/mep_ 2374-8265.10232 . Accessed July 20, 2016.

30. Banatavala N, Doyal L. Knowing when to say "no" on the student elective. Students going on electives abroad need clinical guidelines. BMJ. 1998;316: 1404-1405.

31. Melby M, Loh L, Evert J, Prater C, Lin H, Khan OA. Beyond medical "Missions" to impact-driven Short-term Experiences in Global Health (STEGHs): ethical principles to optimize community benefit and learner experience. Acad Med. 2016;91(5):633-638.

32. Pitt MB, Gladding SP, Majinge CR, Butteris SM. Making global health rotations a two-way street: a model for hosting international residents. Global Pediatr Health. 2016;3:1-7. 